University of Nebraska - Lincoln

DigitalCommons@University of Nebraska - Lincoln

2020

\title{
Quantitative Study of the Energy Changes in Voltage-controlled Spin Crossover Molecular Thin Films
}

Aaron Mosey

Ashley S. Dale

Guanhua Hao

Alpha T. N'diaye

Peter Dowben

See next page for additional authors

Follow this and additional works at: https://digitalcommons.unl.edu/physicsdowben

Part of the Atomic, Molecular and Optical Physics Commons, Condensed Matter Physics Commons, Engineering Physics Commons, and the Other Physics Commons

This Article is brought to you for free and open access by the Research Papers in Physics and Astronomy at DigitalCommons@University of Nebraska - Lincoln. It has been accepted for inclusion in Peter Dowben Publications by an authorized administrator of DigitalCommons@University of Nebraska - Lincoln. 
Authors

Aaron Mosey, Ashley S. Dale, Guanhua Hao, Alpha T. N'diaye, Peter Dowben, and Ruihua Cheng 


\section{Quantitative Study of the Energy Changes in}

\section{Voltage-controlled Spin Crossover Molecular Thin}

\section{Films}

Aaron Mosey, ${ }^{1}$ Ashley S. Dale, ${ }^{1}$ Guanhua Hao, ${ }^{2,3}$ Alpha N'Diaye, ${ }^{3}$ Peter A. Dowben, ${ }^{2}$ Ruihua Cheng $^{1 *}$

${ }^{1}$ Department of Physics, Indiana University-Purdue University Indianapolis, Indianapolis, Indiana 46202, U. S. A.

${ }^{2}$ Department of Physics and Astronomy, University of Nebraska Lincoln, Lincoln, Nebraska 68588, U. S. A.

${ }^{3}$ Advanced Light Source, Lawrence Berkeley National Laboratory, Berkeley, California 94720, U. S. A.

Keywords: Spin crossover, molecular switching, organic gated device, nanoscale organic magnet, non-volatile memory, molecular spintronics.

*corresponding author: Ruihua Cheng, Department of Physics, Indiana University-Purdue University Indianapolis, Indianapolis, Indiana 46202, United States, e mail: rucheng@iupui.edu

This is the author's manuscript of the article published in final edited form as: 


\begin{abstract}
Voltage-controlled nonvolatile isothermal spin state switching of a $\left[\mathrm{Fe}\left\{\mathrm{H}_{2} \mathrm{~B}(\mathrm{pz})_{2}\right\}_{2}\right.$ (bipy)] (pz=tris(pyrazol-1-1y)-borohydride, bipy=2,2'-bipyridine) film, more than 40 to 50 molecular layers thick, is possible when it is adsorbed onto a molecular ferroelectric substrate. Accompanying this high spin and low spin state switching, at room temperature, we observe a remarkable change in conductance, thereby allowing not only non-volatile voltage control of the spin state ("write"), but also current sensing of the molecular spin state ("read"). Monte Carlo Ising model simulations of the high spin state occupancy, extracted from x-ray absorption spectroscopy, indicate that the energy difference between the low spin to high spin state is modified by $110 \mathrm{meV}$. Transport measurements demonstrate that three terminal voltagecontrolled devices can be realized using this system.
\end{abstract}

TOC Graphic

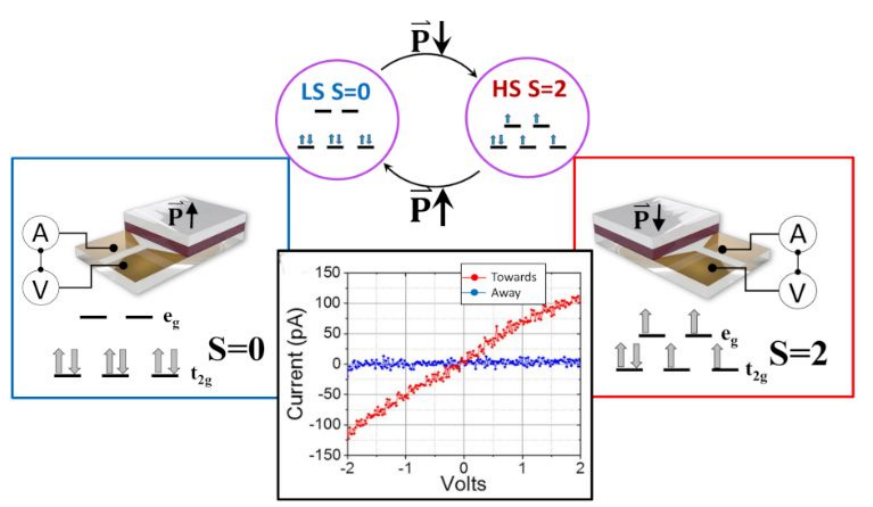


Voltage-controlled molecular multiferroics present an exciting new platform for the exploration of non-volatile spin state switching, providing a basis for successful switchable nanoscale molecular devices. ${ }^{1}$ While electric field control of magnetism in oxide based multiferroics is a well-established field, ${ }^{2}$ demonstrated molecular multiferroic phenomena have recently gained much attention. ${ }^{3-7}$ The molecular spin state may be addressed at the nanoscale ${ }^{8-11}$ and switched with high cyclability without degradation. ${ }^{12}$ Switching speed between the two spin states is potentially in the device-relevant $\mathrm{GHz}$ regime,${ }^{13}$ while molecular based systems are lowcost and can be produced using high-throughput processes such as stamping and printing. ${ }^{14,15}$ These desirable characteristics provide promising solutions for challenges ${ }^{16-19}$ faced by the nanoelectronics engineering community.

Spin crossover (SCO) transitions, in Fe(II) molecular complexes, may be induced by temperature, pressure, light, magnetic field, or electric field. ${ }^{20-22}$ The fundamental mechanism for SCO transition in Fe(II) coordination compounds resides in the ligand field theory, where the $t_{2 g}$ and $e_{\mathrm{g}}$ bands splitting affects low spin (LS) $\mathrm{S}=0$ and high spin (HS) $\mathrm{S}=2$ spin state occupancy in a reversable spin transition phenomenon. The locking and unlocking of the spin state in $\left[\mathrm{Fe}\left\{\mathrm{H}_{2} \mathrm{~B}(\mathrm{pz})_{2}\right\}_{2}(\right.$ bipy $\left.)\right]$ molecules has been convincingly demonstrated in a number of studies. ${ }^{3,7,23-}$ 25 This nonvolatile locking of spin state has been achieved by adsorption of SCO molecules onto dielectric or polarized surface, $3,7,23,25$ and the spin state, in some examples, can be controlled with an external magnetic field ${ }^{3}$ or electric field (i.e., an applied voltage in the latter case). ${ }^{7,23}$ This 
switching from LS to HS, or the reverse, is accompanied by a profound change in conductivity. ${ }^{7}$ The ability to sense spin state change by current measurement in the picoampere regime, and the voltage control of the spin state via polarization of the ferroelectric substrate, are boons for engineered applications and make the study of multiferroic behaviors of this system accessible. When the molecular environment includes adsorption onto a polarized substrate, the exact nature of the interactions in play, affecting spin state population shifts, is an open question, ${ }^{26}$ especially as cooperative and entropic effects are known to have a role in the spin state bistability. $15,20,22,27,28,29,30,31$

It has been established that a polar interface, such as a ferroelectric substrate $23,25,32$ or the addition of dipolar molecules, ${ }^{33}$ may perturb the activation energies for the low spin to high spin state transition. We present, here, a quantitative study of the energy scale and the accompanying conductance change associated with spin state switching in a layered molecular heterostructure with a thin film of the coordination compound $\left[\mathrm{Fe}\left\{\mathrm{H}_{2} \mathrm{~B}(\mathrm{pz})_{2}\right\}_{2}\right.$ (bipy)], where py $=$ tris(pyrazole1-y1)-borohydride, bipy = 2,2'-bipyridine), adsorbed onto a thin film of ferroelectric polyvinylidene fluoride hexafluoropropylene (PVDF-HFP). The polarization of the ferroelectric was isothermally switched to opposite directions at $298 \mathrm{~K}$ through an external applied voltage, prompting the partial spin state change of the central Fe(II) ion from HS state $\mathrm{S}=2$ to LS state $\mathrm{S}=0$. In this study, a $\left[\mathrm{Fe}\left\{\mathrm{H}_{2} \mathrm{~B}(\mathrm{pz})_{2}\right\}_{2}\right.$ (bipy)] film thickness of more than 40 to 50 molecular layers $(65$ nm thick) was chosen so that the influence of the ferroelectric substrate was diminished, but not completely ineffectual. Here both temperature and voltage have an influence on the spin state, unlike for $\left[\mathrm{Fe}\left\{\mathrm{H}_{2} \mathrm{~B}(\mathrm{pz})_{2}\right\}_{2}\right.$ (bipy)] thin films of less than 20 to 25 molecular layers, where the ferroelectric interface polarization appears to dominate, suppressing the influence of temperature. ${ }^{7}$ 
Three distinct samples were fabricated. Device 1, a multilayered heterostructure illustrated in Figure 1, was used for the x-ray absorption spectroscopy (XAS) experiments. Device 2 and Device 3, illustrated in Figures 4 and 5 respectively, are thin film samples that incorporate interdigitated electrodes for transport measurements. Shown in Figure $4 b$, the electrodes for the transport studies are based on an array of interdigitated Au electrodes $250 \mathrm{~nm}$ thick and $10 \mu \mathrm{m}$ wide with an intradigit spacing of $5 \mu \mathrm{m}$.

Device 1 was constructed as follows: A bottom electrode consisting of an $80 \mathrm{~nm}$ Ti thin film was deposited on a silicon substrate by DC magnetron sputtering in high vacuum, followed by a $20 \mathrm{~nm}$ layer of PVDF-HFP produced by Langmuir-Blodgett (LB) deposition, then a $65 \mathrm{~nm}$ layer of $\left[\mathrm{Fe}\left\{\mathrm{H}_{2} \mathrm{~B}(\mathrm{pz})_{2}\right\}_{2}\right.$ (bipy)] was grown on top of the ferroelectric PVDF-HFP via thermal evaporation in high vacuum. The PVDF-HFP thin films were fabricated using layer-by-layer LB deposition following established methods, ${ }^{34,35}$ while thermal deposition of the $\left[\mathrm{Fe}\left\{\mathrm{H}_{2} \mathrm{~B}(\mathrm{pz})_{2}\right\}_{2}\right.$ (bipy)] was performed following the same procedure as our previous experiments $3,7,23,24,25$ and has been adopted by others. ${ }^{36}$ Poling of the ferroelectric layer was achieved by placing a removeable electrode which is a copper plate mounted on a micrometer stage on top of the sample and applying a voltage $(10 \mathrm{~V})$ across the heterostructure. The applied voltage created an electric field of $\sim 120 \mathrm{MV} / \mathrm{m}$ perpendicular to the plane of the structure, which is above the coercive field $(\sim 100 \mathrm{MV} / \mathrm{m})$ required to create a single, polarized domain for PVDFHFP. ${ }^{37}$

X-ray absorption spectroscopy, in total electron yield (TEY) mode at the $\mathrm{Fe} \mathrm{L}_{3}$ edge, was used to probe the unoccupied Fe weighted $e_{g}$ and $t_{2 g}$ molecular orbitals of $\left[\mathrm{Fe}\left\{\mathrm{H}_{2} \mathrm{~B}(\mathrm{pz})_{2}\right\}_{2}(\mathrm{bipy})\right]$, as a function of the ferroelectric polarization of the adjacent PVDF-HFP thin film. This provided a clear picture that the spin state of the $\left[\mathrm{Fe}\left\{\mathrm{H}_{2} \mathrm{~B}(\mathrm{pz})_{2}\right\}_{2}\right.$ (bipy)] thin film depends upon the 
polarization direction of the PVDF-HFP layer. Measurements were done at the Advanced Light Source at Lawrence Berkeley National Laboratory on bending magnet beamline 6.3.1, with TEY mode configured using circularly polarized, positive helicity photons with a photon flux of $10^{11}$ photons $/ \mathrm{sec} / 0.1 \% \mathrm{BW}$. These parameters are the same as used in prior studies. ${ }^{7,23,25,27}$ The intensity of the X-ray beam was tuned in order to limit photoactivation of the molecule yet maintain an acceptable TEY signal.

In-plane conductance measurements were taken on Device 2 and Device 3. Device 2, shown in Figure 4b, was fabricated to measure the conductance as a function of temperature only, and consists of $65 \mathrm{~nm}$ of $\left[\mathrm{Fe}\left\{\mathrm{H}_{2} \mathrm{~B}(\mathrm{pz})_{2}\right\}_{2}\right.$ (bipy)] deposited directly on the interdigitated electrodes, mentioned above. Device 3 was used to characterize the spin state dependent conductance attributable to changes in the ferroelectric polarization, either up or down perpendicular to the plane (i.e. along the normal), and was prepared as follows: a $65 \mathrm{~nm}\left[\mathrm{Fe}\left\{\mathrm{H}_{2} \mathrm{~B}(\mathrm{pz})_{2}\right\}_{2}(\right.$ bipy $\left.)\right]$ thin film was grown directly on the interdigitated electrode array, $20 \mathrm{~nm}$ of ferroelectric PVDF-HFP was then deposited upon this layer, and a top electrode of $80 \mathrm{~nm}$ Au grown by thermal evaporation under high vacuum to avoid damaging the organic layers. The heterostructure was polarized by applying a voltage around $10 \mathrm{~V}$ between the bottom interdigitated electrodes and top Au electrode. Conductance measurements were done using a two-probe technique with an applied voltage source and current readout by a pico-ammeter. 


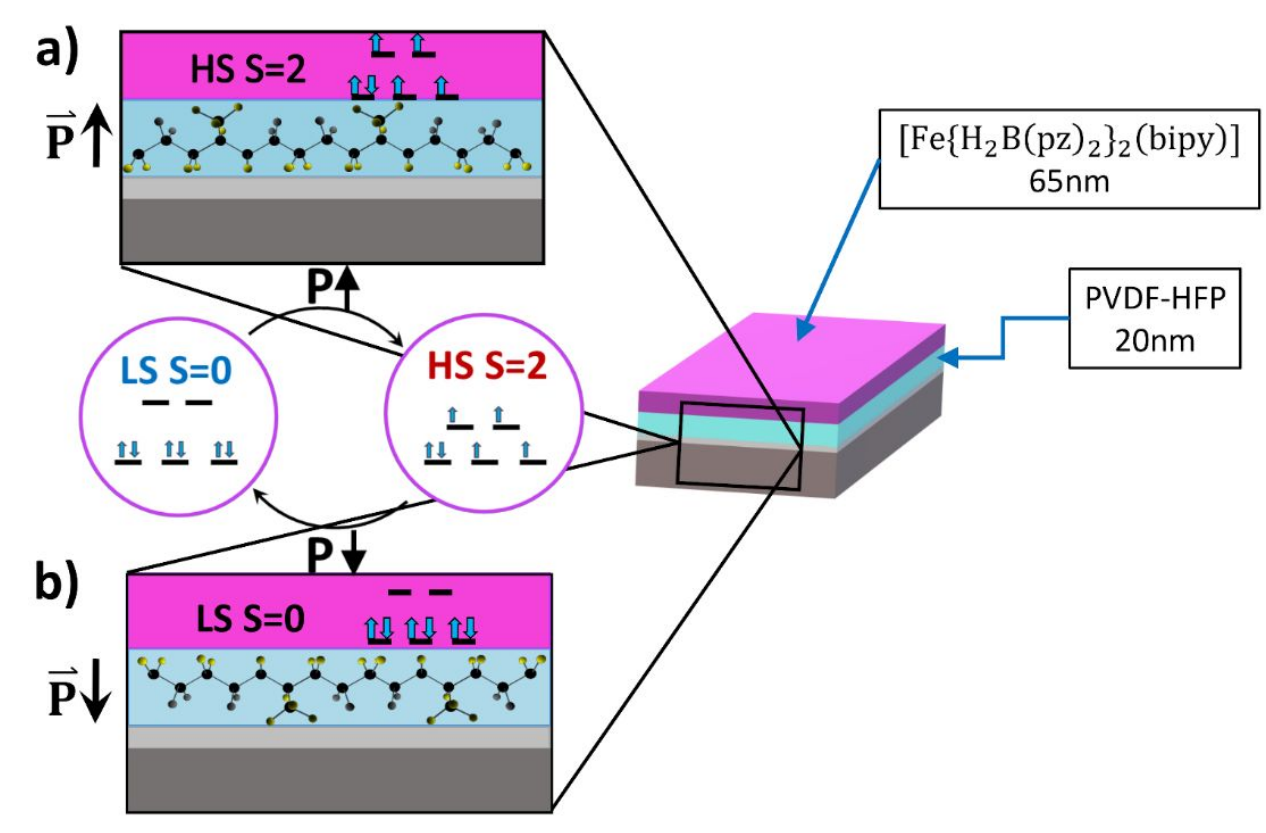

Figure 1. The configuration for multilayered thin film samples (Device 1) used to characterize the spin state of the $[\mathrm{Fe}\{\mathrm{H} 2 \mathrm{~B}(\mathrm{pz}) 2\} 2$ (bipy)] (red) when coupled to the polarization of a ferroelectric PVDF-HFP layer (blue). From bottom to top, the structure is: silicon substrate, bottom electrode of $80 \mathrm{~nm}$ titanium, $20 \mathrm{~nm}$ PVDF-HFP, and $65 \mathrm{~nm}$ $[\mathrm{Fe}\{\mathrm{H} 2 \mathrm{~B}(\mathrm{pz}) 2\} 2($ bipy $)]$.

Using XAS, we have confirmed the prior observation ${ }^{7,23}$ that when the ferroelectric PVDFHFP is polarized up (schematically shown in Figure 1a), the $\left[\mathrm{Fe}\left\{\mathrm{H}_{2} \mathrm{~B}(\mathrm{pz})_{2}\right\}_{2}(\right.$ bipy) $]$ prefers the HS state with $\mathrm{S}=2$, and when the ferroelectric PVDF-HFP is polarized down (schematically shown in 
Figure 1b), the LS state with $S=0$ is favored. Yet, we find that for $\left[\mathrm{Fe}\left\{\mathrm{H}_{2} \mathrm{~B}(\mathrm{pz})_{2}\right\}_{2}(\mathrm{bipy})\right]$ films 65

$\mathrm{nm}$ thick, the spin state occupancy is dependent not only upon the direction of ferroelectric polarization but is also temperature dependent. The switching of HS to LS states at room temperature, through a voltage control, is clearly evident in the XAS measurements, as shown in Figure 2. In the absence of external electric stimuli, $\left[\mathrm{Fe}\left\{\mathrm{H}_{2} \mathrm{~B}(\mathrm{pz})_{2}\right\}_{2}(\right.$ bipy $\left.)\right]$ is naturally in the HS state at $298 \mathrm{~K}$, and the typical reported $\mathrm{T}_{1 / 2}$ from the HS state to LS state is around $167 \mathrm{~K} .{ }^{27,40}$ Figure 2a shows the temperature dependent XAS data for $\left[\mathrm{Fe}\left\{\mathrm{H}_{2} \mathrm{~B}(\mathrm{pz})_{2}\right\}_{2}(\right.$ bipy $\left.)\right]$ thin films deposited on a ferroelectric PVDF-HFP substrate when PVDF-HFP is polarized "up", i.e., toward the SCO layer, as schematically illustrated in Figure 1a, while Figure $2 \mathrm{~b}$ shows the data when PVDF-HFP is polarized "down" or away from the SCO layer, as schematically illustrated in Figure 1b. When $\left[\mathrm{Fe}\left\{\mathrm{H}_{2} \mathrm{~B}(\mathrm{pz})_{2}\right\}_{2}(\mathrm{bipy})\right]$ is in the LS state, the $3 \mathrm{~d}$ electrons occupy the $t_{2 g}$ in pairs, leaving the $e_{g}$ molecular orbital empty. This unoccupied $e_{g}$ molecular orbital is observable in the $2 p_{3 / 2}(\mathrm{Fe}$ $\mathrm{L}_{3}$ ) XAS spectra as a major peak, at a photon energy of about $710 \mathrm{eV}$. In the high spin state, the $e_{g}$ is partially populated with the $t_{2 g}$ orbitals subsequently partly depopulated. This leads to a signature of the $t_{2 g}$ in the XAS spectra at the $\mathrm{Fe}_{3}\left(2 p_{3 / 2}\right)$ edge with features appearing at photon energies of $704 \mathrm{eV}$ and $708 \mathrm{eV}$, while the feature at $710 \mathrm{eV}$, characteristic of the $e_{g}$ molecular orbital, decreases. 


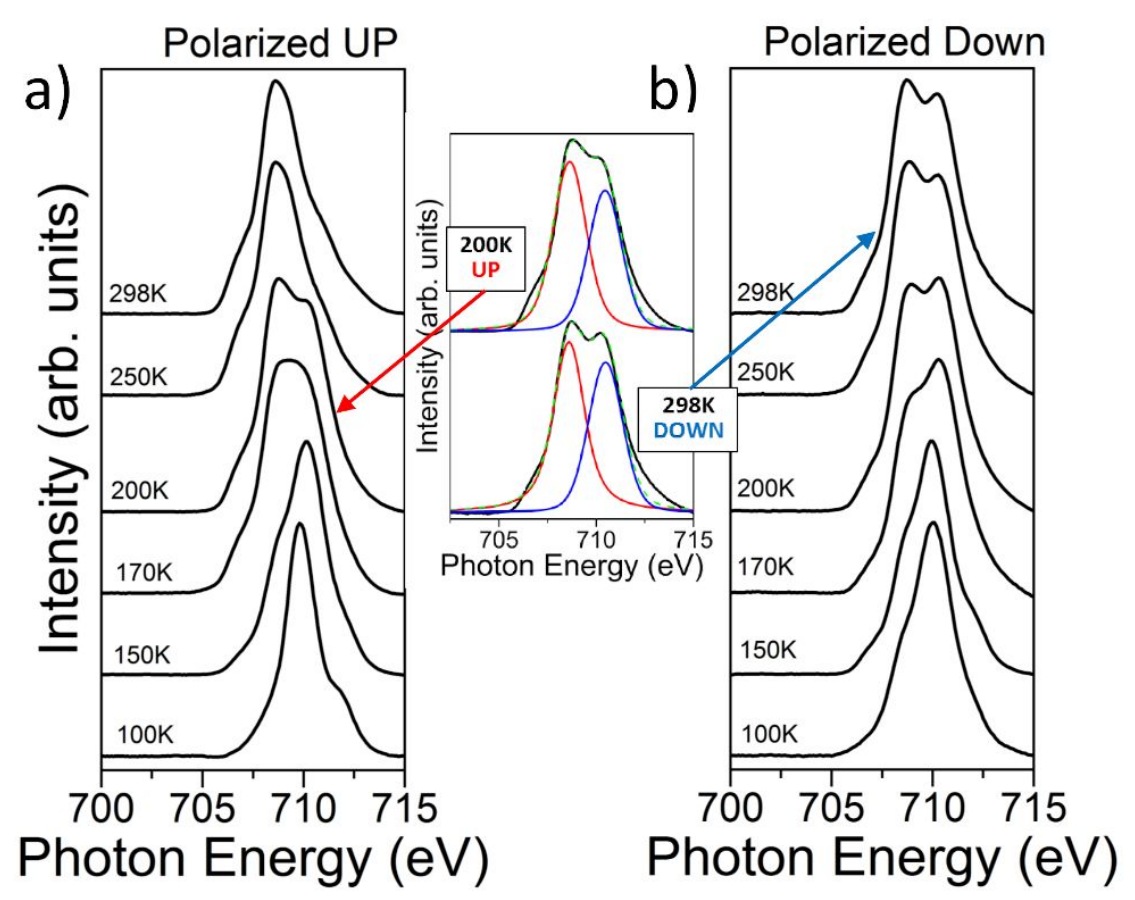

Figure 2. The X-ray absorption spectra showing the changing intensities of the $e_{g}$ and $t_{2 g}$ features for $\left[\mathrm{Fe}\left\{\mathrm{H}_{2} \mathrm{~B}(\mathrm{pz})_{2}\right\}_{2}\right.$ (bipy)], as a function of temperature and substrate ferroelectric polarization. In a, the PVDF-HFP substrate is polarized "up" or toward the SCO layer. In b, the PVDF-HFP substrate is polarized "down" or away from the SCO film as unoccupied states of the $e_{g}$ orbital above the transition temperature are observed, indicating that the sample can be locked into the low spin $\mathrm{S}=0$ state past the transition temperature of $167 \mathrm{~K}$. Each spectrum is deconvoluted into HS dominant (red curve) and LS dominant (blue curve) peaks, shown in the inset between a and $\mathbf{b}$.

There are significant differences in the XAS spectra for $\left[\mathrm{Fe}\left\{\mathrm{H}_{2} \mathrm{~B}(\mathrm{pz})_{2}\right\}_{2}(\mathrm{bipy})\right]$ when the PVDF-HFP substrate is polarized "down" versus polarized "up". Figure $2 \mathrm{~b}$ shows the temperature dependent XAS data for $\left[\mathrm{Fe}\left\{\mathrm{H}_{2} \mathrm{~B}(\mathrm{pz})_{2}\right\}_{2}\right.$ (bipy)] deposited on a ferroelectric PVDF-HFP substrate when PVDF-HFP is polarized "down" or away from the SCO layer, as illustrated in Figure 1b, 
and the signature of the $e_{g}$ unoccupied molecular orbital (at a photon energy of $710 \mathrm{eV}$ ) remains strong at all temperatures. This indicates that the sample can be locked mostly (but imperfectly) into the LS S $=0$ state above the powder transition temperature of $167 \mathrm{~K} \cdot{ }^{4,27,40}$ As shown in Figure 2a, when PVDF-HFP is polarized "up" or toward the $\left[\mathrm{Fe}\left\{\mathrm{H}_{2} \mathrm{~B}(\mathrm{pz})_{2}\right\}_{2}(\right.$ bipy $\left.)\right]$ thin film layer, as sketched in Figure 1a, the signature of the $e_{g}$ orbital dominates the XAS spectra only below 150 $\mathrm{K}$. When the sample temperature is raised beyond $150 \mathrm{~K}$, when the ferroelectric substrate is polarized "up" or toward the $\left[\mathrm{Fe}\left\{\mathrm{H}_{2} \mathrm{~B}(\mathrm{pz})_{2}\right\}_{2}\right.$ (bipy)] thin film, a distinct peak is evident in the region of the photon energy of $708 \mathrm{eV}$, accompanied by a small shoulder at $704 \mathrm{eV}$, characteristic of the $t_{2 g}$ unoccupied molecular orbitals, as noted above, and a signature of the $\mathrm{S}=2 \mathrm{HS}$ state.
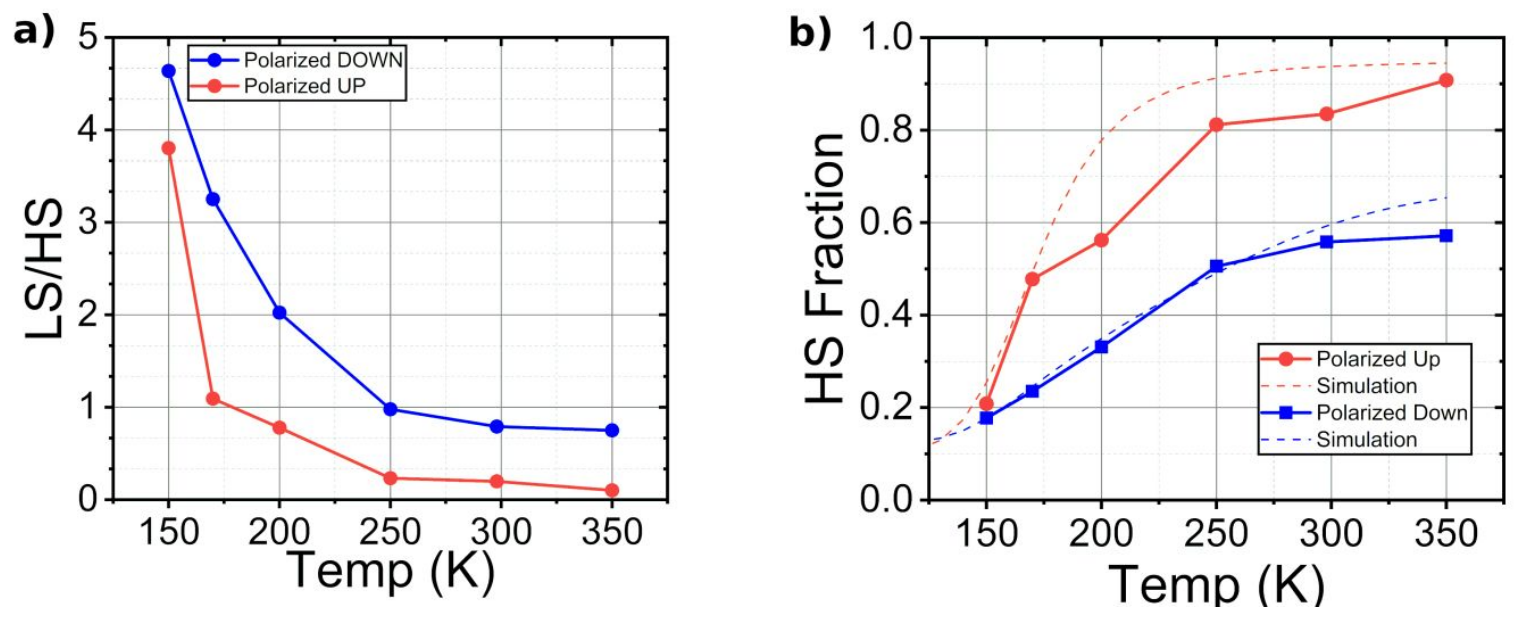

Figure 3. Comparable ratios of low spin (LS) state to high spin (HS) state for different temperatures and polarization, as measured by XAS on Device 1. Figure 3a is a plot of $\gamma_{L S}$ (LS/HS ratio) as a function of temperature for two different polarized directions, as derived from the XAS spectra; the red data curve is for the ferroelectric PVDF-HFP polarized up and the blue data curve is for PVDF-HFP polarized down. HS Fraction as a 
function of temperature is plotted in $\mathbf{b}$, with the modified Monte Carlo Ising model
simulation superimposed. Considering the evolution of density of states for $t_{2 g}$ and $e_{g}$ orbitals as a function of changing temperature, in the different electric field orientation as produced by the polarized ferroelectric layer, the energetics involved in the electric field induced transition between the HS and LS states may be examined. As shown in the inset between Figure $2 a$ and $2 b$, the resolved peaks of HS and LS states for all the spectra taken at different temperatures with two opposite polarization directions indicate that comparable LS to HS state ratios $\left(\gamma_{L S}\right)$ exist at $200 \mathrm{~K}$ for the ferroelectric substrate polarized "up" while a similar ratio is observed at $298 \mathrm{~K}$ for the ferroelectric substrate polarized "down". The spin state occupancy, as a function of temperature and ferroelectric substrate polarization, is summarized in Figure 3. The LS to HS state ratio data in Figure $3 a$ and the HS state occupancy in Figure 3b consistently show that the choice of substrate polarization creates a temperature difference between the relative HS to LS state occupancies. Considering the LS to HS state ratio $\gamma_{L S}=1$, we can clearly observe that the SCO transition takes 
place in the temperature region of $170 \mathrm{~K}$ for "up" and $250 \mathrm{~K}$ for "down" or a temperature difference of around $80 \mathrm{~K}$ in assessing the effect of the substrate polarization (toward or away from the SCO molecular layer, i.e., polarized up or down) on the high spin state occupancy.

The phase transition between HS and LS states of SCO molecules can be simulated by an Ising-like model, where the two discrete values correspond to the HS and LS states, respectively. ${ }^{38}$ In order to understand the mechanism of how the electric polarization affects the transition temperature in the molecular $\left[\mathrm{Fe}\left\{\mathrm{H}_{2} \mathrm{~B}(\mathrm{pz})_{2}\right\}_{2}\right.$ (bipy)]/PVDF-HFP bilayer system, we use a two dimensional Monte Carlo Ising model ${ }^{39,40}$ simulation to generate the theoretical data shown in Figure $3 \mathrm{~b}$. The typical Hamiltonian expression for a SCO transition is

$$
\mathrm{H}=-\mathrm{J} \sum_{(i, j)} S(i, j) S(i \pm 1, j \pm 1)+\left(\frac{\Delta}{2}-\frac{k_{B} T}{2} \ln g\right) \sum_{(i, j)} S(i, j),
$$

where $\mathrm{J}$ is the interaction between molecules, the LS and HS take +1 and -1 for spin operator $S(i, j), \Delta$ is the energy difference between HS and LS states of isolated molecules, and In $g$ is the ratio of HS degeneracy to LS degeneracy. Simulation data, 
shown as the dashed lines in Figure 3b, indicates that the energy difference $\Delta$ between HS and LS states is approximately $88 \mathrm{meV}$ when the ferroelectric substrate is polarized up while parameter $\Delta$ increases to approximately $198 \mathrm{meV}$ when the polarization is switched to the opposite direction. The energy difference in the $\Delta$, between HS and LS states, as a result of the different substrate ferroelectric polarizations, is approximately $110 \mathrm{meV}$. This ferroelectric substrate polarization dependent energy difference $\Delta$ is indicative of significant changes within the $\left[\mathrm{Fe}\left\{\mathrm{H}_{2} \mathrm{~B}(\mathrm{pz})_{2}\right\}_{2}(\mathrm{bipy})\right]$ thin film that are clearly substrate dependent. While the substrate has been seen previously to affect the spin state bistability, ${ }^{7,23-25,27}$ here the results show that the polarization direction, of the ferroelectric substrate, plays an important role. Considering that the electrical dipole moment in $\left[\mathrm{Fe}\left\{\mathrm{H}_{2} \mathrm{~B}(\mathrm{pz})_{2}\right\}_{2}\right.$ (bipy)] is 4.7 Debye for the LS state, ${ }^{25}$ we estimate the electrical field generated from the polarized ferroelectric PVDF-HFP is at least $4.9 \times 10^{9} \mathrm{~V} / \mathrm{m}$, at the interface, when the field is parallel with the $\left[\mathrm{Fe}\left\{\mathrm{H}_{2} \mathrm{~B}(\mathrm{pz})_{2}\right\}_{2}(\mathrm{bipy})\right]$ dipole moment. In general, these two vectors are unlikely to be perfectly aligned in parallel, implying that the actual electric field due to the polarization of the PVDF-HFP may be much higher than this estimated value. This result is in agreement with our previous study for PVDF thin 
films. ${ }^{38}$ The crystallization of the PVDF-HFP layer is crucial to observing this polarization effect, where lack of crystallization will result in the random distribution of dipole moments and diminish the net interface dipole. Improved order and crystallization of $\beta$-phase PVDF-HFP thin films ${ }^{41}$ allows for more uniform polarization and thus higher electric field. ${ }^{42}$ This does not exclude the possibility that interactions at the interface between the PVDFHFP layer and the $\left[\mathrm{Fe}\left\{\mathrm{H}_{2} \mathrm{~B}(\mathrm{pz})_{2}\right\}_{2}\right.$ (bipy)] propagate through the $\left[\mathrm{Fe}\left\{\mathrm{H}_{2} \mathrm{~B}(\mathrm{pz})_{2}\right\}_{2}\right.$ (bipy)] thin film and this interaction also depends on a high degree of crystallinity. The electric field is similar in magnitude for a ferroelectric polarization toward or away from the SCO $\left[\mathrm{Fe}\left\{\mathrm{H}_{2} \mathrm{~B}(\mathrm{pz})_{2}\right\}_{2}\right.$ (bipy)] layer, but the interface termination changes from largely hydrogen termination at the interface, with the PVDF-HFP layer poled toward the SCO $\left[\mathrm{Fe}\left\{\mathrm{H}_{2} \mathrm{~B}(\mathrm{pz})_{2}\right\}_{2}(\mathrm{bipy})\right]$ molecular layer, to a fluorine termination for a polarization away from the SCO $\left[\mathrm{Fe}\left\{\mathrm{H}_{2} \mathrm{~B}(\mathrm{pz})_{2}\right\}_{2}(\right.$ bipy $\left.)\right]$ molecular layer. When initially adsorbed onto the substrate, SCO may have a preferential orientation with respect to the PVDF-HFP, and it is sterically hindered from molecular rotation when the ferroelectric polarization is then reversed. This has some effect, because the intrinsic $\left[\mathrm{Fe}\left\{\mathrm{H}_{2} \mathrm{~B}(\mathrm{pz})_{2}\right\}_{2}(\mathrm{bipy})\right]$ dipole is then perturbed differently as the interface electric field changes sign. However, presently there 
is no direct evidence as to the mechanism for the ferroelectric substrate polarization perturbation of the $\left[\mathrm{Fe}\left\{\mathrm{H}_{2} \mathrm{~B}(\mathrm{pz})_{2}\right\}_{2}\right.$ (bipy)] spin states.

These XAS data, supported by the 2D Ising model simulations, suggest a profound interaction between the $\left[\mathrm{Fe}\left\{\mathrm{H}_{2} \mathrm{~B}(\mathrm{pz})_{2}\right\}_{2}\right.$ (bipy)] spin crossover layer and the ferroelectric at the interface. The lack of a more complete adoption of the high spin state at $200 \mathrm{~K}$, when PVDF-HFP is polarized "up" (Figure 2a), and the signatures of partial occupancy of the low spin state throughout the measured temperature range, when PVDF-HFP is polarized "down" (Figure $2 \mathrm{~b}$ ), is the result of a thicker $\left[\mathrm{Fe}\left\{\mathrm{H}_{2} \mathrm{~B}(\mathrm{pz})_{2}\right\}_{2}\right.$ (bipy)] spin crossover film. In some prior studies, where the $\left[\mathrm{Fe}\left\{\mathrm{H}_{2} \mathrm{~B}(\mathrm{pz})_{2}\right\}_{2}\right.$ (bipy)] film was only a few molecular layers ${ }^{23}$ (less than $12 \mathrm{~nm})$ of $\left[\mathrm{Fe}\left\{\mathrm{H}_{2} \mathrm{~B}(\mathrm{pz})_{2}\right\}_{2}\right.$ (bipy)], the HS and LS states were more strongly favored over a broad range of temperatures when the ferroelectric substrate was polarized "up" or "down" respectively. Cooperative and surface effects are known, and could also influence the measured spin state occupancy. ${ }^{27}$ 

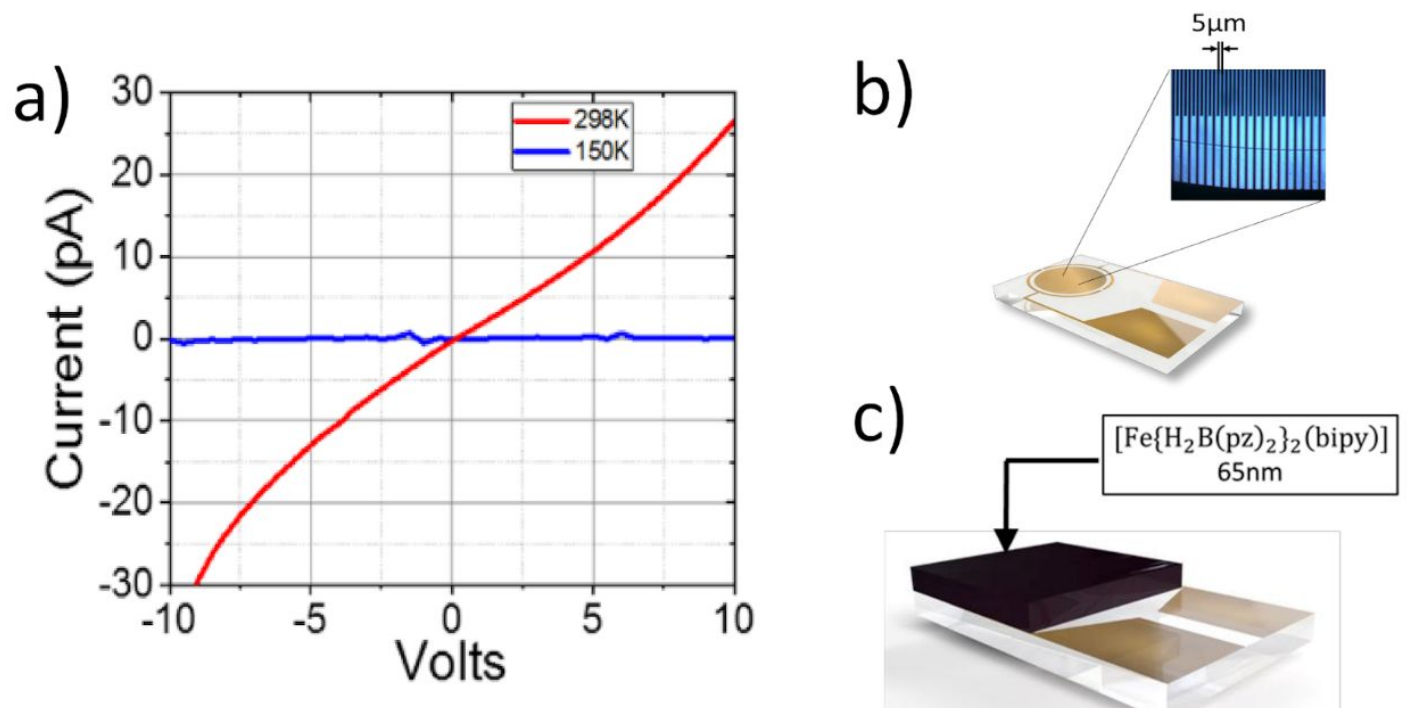

Figure 4. The differences in conductance for $\left[\mathrm{Fe}\left\{\mathrm{H}_{2} \mathrm{~B}(\mathrm{pz})_{2}\right\}_{2}(\mathrm{bipy})\right]$ thin films for the high spin (HS) dominated state verses the low spin (LS) dominated state. Figure a shows the conductance measured across Device 2 at room temperature $(298 \mathrm{~K})$ and below $T_{1 / 2}$, the transition temperature $(150 \mathrm{~K})$. Interdigitated electrodes with a spacing of $5 \mu \mathrm{m}$ were used as the basis for all transport measurement, as shown in b. As shown in c, Device 2 consists of a $\left[\mathrm{Fe}\left\{\mathrm{H}_{2} \mathrm{~B}(\mathrm{pz})_{2}\right\}_{2}\right.$ (bipy)] thin film deposited directly on interdigitated electrodes.

Conductance changes, associated with the different spin state change, are well documented in SCO materials, ${ }^{12,22,43-54}$ and can be used to induced conductance changes in an adjacent graphene layer. ${ }^{55}$ Yet nonvolatile changes in the conductivity of 
SCO molecules, associated with a static polarization of an adjacent ferroelectric layer, have just recently been characterized. ${ }^{7}$ The conventional approach to induce the SCO transition from HS to LS is through temperature control, and this holds for the SCO $\left[\mathrm{Fe}\left\{\mathrm{H}_{2} \mathrm{~B}(\mathrm{pz})_{2}\right\}_{2}(\right.$ bipy $\left.)\right]$ as well. As shown in Figure $4 \mathrm{a}$, the I-V curves for temperature at $298 \mathrm{~K}$ and $150 \mathrm{~K}$ are plotted. Data for the $298 \mathrm{~K}$ measurement clearly show a nonlinear response, well above the spin transition $T_{1 / 2}$, at $167 \mathrm{~K}$. Below the spin transition $T_{1 / 2}$, at $150 \mathrm{~K}$. a dramatic decrease in conductance, by about two orders of magnitude, is observed, consistent with the larger highest occupied molecular orbital (HOMO) to lowest unoccupied molecular orbital (LUMO) gap $\left[\mathrm{Fe}\left\{\mathrm{H}_{2} \mathrm{~B}(\mathrm{pz})_{2}\right\}_{2}(\mathrm{bipy})\right]^{23}$ and the resulting low conductance in LS states noted elsewhere. ${ }^{7}$

Here the temperature dependent conductance of SCO $\left[\mathrm{Fe}\left\{\mathrm{H}_{2} \mathrm{~B}(\mathrm{pz})_{2}\right\}_{2}(\right.$ bipy $\left.)\right]$ thin film is mediated by the ferroelectric substrate polarization as well as temperature; Figure 5 shows the polarization dependent conductance data measured at $298 \mathrm{~K}$ for the multilayer system of the $\left[\mathrm{Fe}\left\{\mathrm{H}_{2} \mathrm{~B}(\mathrm{pz})_{2}\right\}_{2}(\right.$ bipy $\left.)\right] / P V D F-H F P$ thin film heterostructure, as described in the configuration of Device 3. When the polarization of the ferroelectric layer 
is polarized toward the $\left[\mathrm{Fe}\left\{\mathrm{H}_{2} \mathrm{~B}(\mathrm{pz})_{2}\right\}_{2}\right.$ (bipy)] layer, the $\mathrm{HS}$ state is dominant, and a higher conductance is observed. The conductance of the $\left[\mathrm{Fe}\left\{\mathrm{H}_{2} \mathrm{~B}(\mathrm{pz})_{2}\right\}_{2}\right.$ (bipy)] thin film is clearly mediated by the polarization of the ferroelectric PVDF-HFP substrate, which in turn can be controlled by a gate voltage and is non-volatile, creating a straightforward route toward a three terminal molecular device. ${ }^{1}$

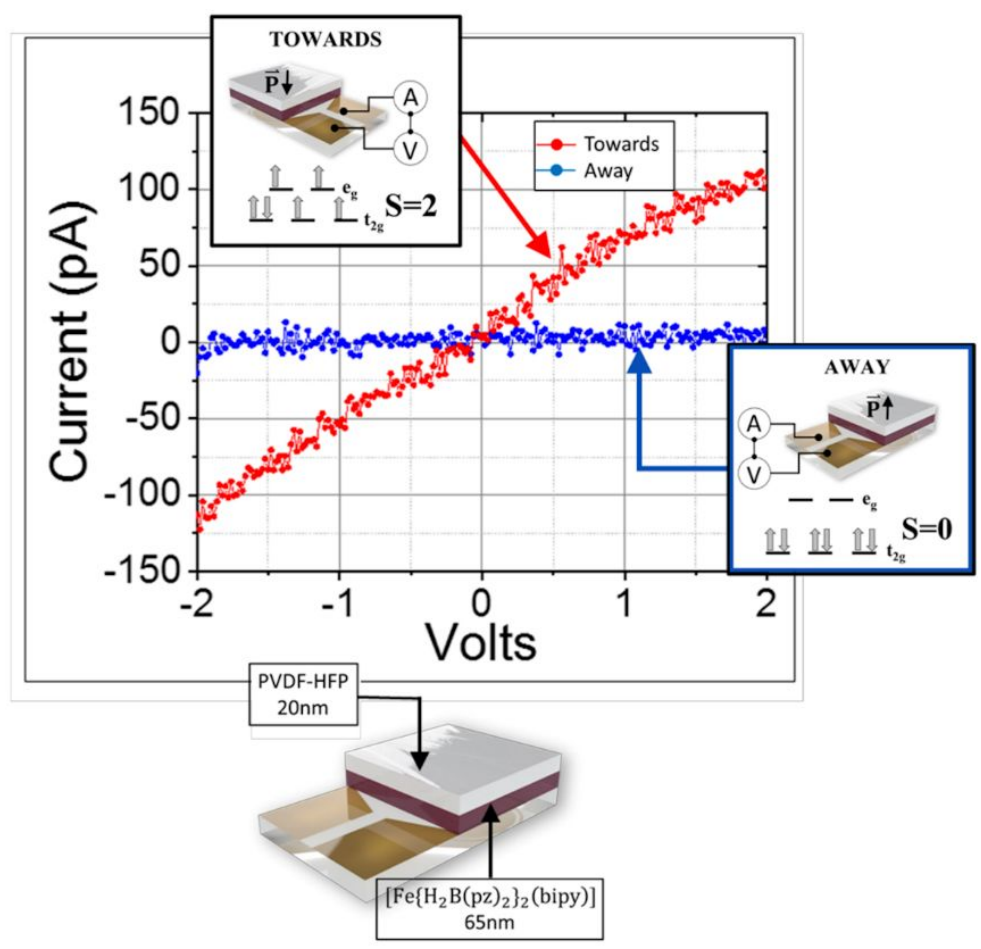

Figure 5. The change in conductance observed with different ferroelectric polarization directions. Transport measurements were taken across a device with the ferroelectric layer adjacent to the SCO layer. Polarizing the ferroelectric toward the $[\mathrm{Fe}\{\mathrm{H} 2 \mathrm{~B}(\mathrm{pz}) 2\} 2$ (bipy)] layer results in $\mathrm{HS} \mathrm{S}=2$, and a larger conductance. Polarization of 
the ferroelectric away from the $[\mathrm{Fe}\{\mathrm{H} 2 \mathrm{~B}(\mathrm{pz}) 2\} 2$ (bipy)] layer gives the $\mathrm{LS} \mathrm{S}=0$ state and lower conductance by two orders of magnitude. Device 3 is schematically illustrated.

These studies clearly demonstrate that a bi-stable isothermal switching of the spin state and conductance in $\left[\mathrm{Fe}\left\{\mathrm{H}_{2} \mathrm{~B}(\mathrm{pz})_{2}\right\}_{2}\right.$ (bipy)] thin films may be controlled by the application of an external voltage when adsorbed onto a ferroelectric substrate. Insight into the switching mechanism is gained through XAS and theoretical modeling, further unveiling the mechanism of switching. Broadening of the energy gap between the HS and LS states, as characterized by XAS and examined with theoretical modeling, gives an activation energy for this process of about $110 \mathrm{meV}$. Moreover, the bi-stable spin transition is accompanied by a measurable change in transport properties around two orders of magnitude between the HS and LS states on devices where the SCO is triggered by an applied external voltage. This supplies an intriguing, feasible platform for the design of gated voltage-controlled molecular spintronic devices. 


\author{
AUTHOR INFORMATION \\ Corresponding Author \\ ${ }^{*}$ Ruihua Cheng - Department of Physics, Indiana University-Purdue University \\ Indianapolis, 402 North Blackford Street, Indianapolis, Indiana 46202, United States of \\ America; https://orcid.org/0000-0003-1579-8097 Email: rucheng@iupui.edu
}

\title{
Author Contributions
}

Aaron Mosey - Department of Physics, Indiana University-Purdue University Indianapolis, 402 North Blackford Street, Indianapolis, Indiana 46202, United States of America https://orcid.org/0000-0003-1513-3968 
Guanhua Hao - Department of Physics and Astronomy, University of Nebraska Lincoln,

Lincoln, Nebraska 6588, United States of America. https://orcid.org/0000-0003-32816816

Alpha N'Diaye - Advanced Light Source, Lawrence Berkeley National Laboratory, Berkeley, California 94720, United States of America. https://orcid.org/0000-0001-94299776

Ashley S. Dale - Department of Physics, Indiana University-Purdue University Indianapolis, 402 North Blackford Street, Indianapolis, Indiana 46202, United States of America. https://orcid.org/0000-0001-8233-5258

Peter Dowben - Department of Physics and Astronomy, University of Nebraska Lincoln, Lincoln, Nebraska 6588, United States of America. https://orcid.org/0000-0002-21984710

Ruihua Cheng - Department of Physics, Indiana University-Purdue University Indianapolis, 402 North Blackford Street, Indianapolis, Indiana 46202, United States of America; https://orcid.org/0000-0003-1579-8097 Email: rucheng@iupui.edu 


\section{Funding Sources}

This research was supported by the National Science Foundation through NSF-Chem

1565692 [A. Mosey, A. Dale, G. Hao, R. Cheng, P. A. Dowben]. Use of the Advanced

Light Source, Lawrence Berkeley National Laboratory, was supported by the U.S.

Department of Energy (DOE) under contract no. DE-AC02-05CH11231.

\section{ACKNOWLEDGMENT}

This research was supported by the National Science Foundation through NSF-Chem

1565692 [A. Mosey, A. Dale, G. Hao, R. Cheng, P. A. Dowben]. Use of the Advanced

Light Source, Lawrence Berkeley National Laboratory, was supported by the U.S.

Department of Energy (DOE) under contract no. DE-AC02-05CH11231. The authors

would like to acknowledge the artistic contributions to Figures 4 and 5 by Sara Dale. 


\section{REFERENCES}

(1) Hao, G.; Cheng, R.; Dowben, P. A. The Emergence of the Local Moment Molecular

Spin Transistor. J. Phys. Condens. Matter 2020, 32 (23). https://doi.org/10.1088/1361$648 X / a b 74 \mathrm{e} 4$.

(2) Vaz, C. A. F. Electric Field Control of Magnetism in Multiferroic Heterostructures.

J. Phys. Condens. Matter 2012, 24 (33). https://doi.org/10.1088/0953$8984 / 24 / 33 / 333201$.

(3) Zhang, X.; N'Diaye, A. T.; Jiang, X.; Zhang, X.; Yin, Y.; Chen, X.; Hong, X.; Xu, X.;

Dowben, P. A. Indications of Magnetic Coupling Effects in Spin Cross-over Molecular Thin Films. Chem. Commun. 2018, 54 (8), 944-947. https://doi.org/10.1039/c7cc08246k.

(4) Zapf, V. S.; Sengupta, P.; Batista, C. D.; Nasreen, F.; Wolff-Fabris, F.; PaduanFilho, A. Magnetoelectric Effects in an Organometallic Quantum Magnet. Phys. Rev. B Condens. Matter Mater. Phys. 2011, $83 \quad$ (14), 22-25. https://doi.org/10.1103/PhysRevB.83.140405. 
(5) Zapf, V. S.; Kenzelmann, M.; Wolff-Fabris, F.; Balakirev, F.; Chen, Y. Magnetically Induced Electric Polarization in an Organometallic Magnet. Phys. Rev. B - Condens. Matter Mater. Phys. 2010, 82 (6), 1-4. https://doi.org/10.1103/PhysRevB.82.060402.

(6) Chikara, S.; Gu, J.; Zhang, X.-G. G.; Cheng, H.-P. P.; Smythe, N.; Singleton, J.;

Scott, B.; Krenkel, E.; Eckert, J.; Zapf, V. S. Magnetoelectric Behavior via a Spin State Transition. Nat. Commun. 2019, 10 (1), 4043. https://doi.org/10.1038/s41467-019-119673.

(7) Hao, G.; Mosey, A.; Jiang, X.; Yost, A. J. J.; Sapkota, K. R. R.; Wang, G. T. T.; Zhang, X.; Zhang, J.; N'Diaye, A. T. T.; Cheng, R.; Xu, X.; Dowben, P. A. A. Nonvolatile Voltage Controlled Molecular Spin State Switching. Appl. Phys. Lett. 2019, 114 (3), 032901. https://doi.org/10.1063/1.5054909.

(8) Larionova, J.; Salmon, L.; Guari, Y.; Tokarev, A.; Molvinger, K.; Molnár, G.; Bousseksou, A. Towards the Ultimate Size Limit of the Memory Effect in Spin-Crossover Solids. Angew. Chemie - Int. Ed. 2008, 47 (43), 8236-8240. https://doi.org/10.1002/anie.200802906. 
(9) Shepherd, H. J.; Molnár, G.; Nicolazzi, W.; Salmon, L.; Bousseksou, A. Spin Crossover at the Nanometre Scale. Eur. J. Inorg. Chem. 2013, No. 5-6, 653-661. https://doi.org/10.1002/ejic.201201205.

(10) Piedrahita-Bello, M.; Martin, B.; Salmon, L.; Molnár, G.; Demont, P.; Bousseksou, A. Mechano-Electric Coupling in P(VDF-TrFE)/Spin Crossover Composites. J. Mater. Chem. C 2020, 8 (18), 6042-6051. https://doi.org/10.1039/d0tc00780c.

(11) Usmani, S.; Mikolasek, M.; Gillet, A.; Sanchez Costa, J.; Rigoulet, M.; Chaudret, B.; Bousseksou, A.; Lassalle-Kaiser, B.; Demont, P.; Molnár, G.; Salmon, L.; Carrey, J.; Tricard, S. Spin Crossover in Fe(Triazole)-Pt Nanoparticle Self-Assembly Structured at the Sub-5 Nm Scale. Nanoscale 2020, 12 (15), 8180-8187. https://doi.org/10.1039/d0nr02154g.

(12) Lefter, C.; Rat, S.; Costa, J. S.; Manrique-Juárez, M. D.; Quintero, C. M.; Salmon, L.; Séguy, I.; Leichle, T.; Nicu, L.; Demont, P.; Rotaru, A.; Molnár, G.; Bousseksou, A. Current Switching Coupled to Molecular Spin-States in Large-Area Junctions. Adv. Mater. 2016, 28 (34), 7508-7514. https://doi.org/10.1002/adma.201601420. 
(13) Senthil Kumar, K.; Ruben, M. Emerging Trends in Spin Crossover (SCO) Based

Functional Materials and Devices. Coord. Chem. Rev. 2017, 346, 176-205. https://doi.org/10.1016/j.ccr.2017.03.024.

(14) Cavallini, M. Status and Perspectives in Thin Films and Patterning of Spin Crossover Compounds. Phys. Chem. Chem. Phys. 2012, 14 (34), 11867-11876. https://doi.org/10.1039/c2cp40879a.

(15) Mallah, T.; Cavallini, M. Surfaces, Thin Films and Patterning of Spin Crossover Compounds. Comptes Rendus Chim. 2018, 21 (12), 1270-1286. https://doi.org/10.1016/j.crci.2018.02.007.

(16) Claeys, C. Trends and Challenges in Micro- and Nanoelectronics for the next Decade. In Proceedings of the 19th International Conference Mixed Design of Integrated Circuits and Systems - MIXDES 2012; 2012; pp 37-42.

(17) Wang, K. L. Issues of Nanoelectronics: A Possible Roadmap. J. Nanosci. Nanotechnol. 2002, 2 (3), 235-266. https://doi.org/10.1166/jnn.2002.115. 
(18) Tsu, R. Challenges in Nanoelectronics. Nanotechnology 2001, 12 (4), 625-628.

https://doi.org/10.1088/0957-4484/12/4/351.

(19) National Nanotechnology Initiative Signature Initiative: Nanoelectronics for 2020 and Beyond. 2010, pp 1-6.

(20) Gütlich, P.; Garcia, Y.; Goodwin, H. A. Spin Crossover Phenomena in Fe(II) Complexes. Chem. Soc. Rev. 2000, 29 (6), 419-427. https://doi.org/10.1039/b003504l.

(21) Lefter, C.; Tan, R.; Dugay, J.; Tricard, S.; Molnár, G.; Salmon, L.; Carrey, J.; Nicolazzi, W.; Rotaru, A.; Bousseksou, A. Unidirectional Electric Field-Induced Spin-State Switching in Spin Crossover Based Microelectronic Devices. Chem. Phys. Lett. 2016, 644, 138-141. https://doi.org/10.1016/j.cplett.2015.11.036.

(22) Prins, F.; Monrabal-Capilla, M.; Osorio, E. A.; Coronado, E.; van der Zant, H. S. J. Room-Temperature Electrical Addressing of a Bistable Spin-Crossover Molecular System. Adv. Mater. 2011, $23 \quad$ (13), 1545-1549. https://doi.org/10.1002/adma.201003821. 
(23) Zhang, X.; Palamarciuc, T.; Létard, J.-F.; Rosa, P.; Lozada, E. V.; Torres, F.; Rosa,

L. G.; Doudin, B.; Dowben, P. A. The Spin State of a Molecular Adsorbate Driven by the Ferroelectric Substrate Polarization. Chem. Commun. 2014, 50 (18), 2255. https://doi.org/10.1039/c3cc46892e.

(24) Beniwal, S.; Zhang, X.; Mu, S.; Naim, A.; Rosa, P.; Chastanet, G.; Létard, J.-F.;

Liu, J.; Sterbinsky, G. E.; Arena, D. A.; Dowben, P. A.; Enders, A. Surface-Induced Spin State Locking of the $[\mathrm{Fe}(\mathrm{H} 2 \mathrm{~B}(\mathrm{Pz}) 2$ ) 2 (Bipy)] Spin Crossover Complex. J. Phys. Condens. Matter 2016, 28 (20), 206002. https://doi.org/10.1088/0953$8984 / 28 / 20 / 206002$.

(25) Zhang, X.; Costa, P. S.; Hooper, J.; Miller, D. P.; N'Diaye, A. T.; Beniwal, S.; Jiang, X.; Yin, Y.; Rosa, P.; Routaboul, L.; Gonidec, M.; Poggini, L.; Braunstein, P.; Doudin, B.; Xu, X.; Enders, A.; Zurek, E.; Dowben, P. A. Locking and Unlocking the Molecular Spin Crossover Transition. Adv. Mater. 2017, 29 (39), 1-10. https://doi.org/10.1002/adma.201702257. 
(26) Cinchetti, M.; Dediu, V. A.; Hueso, L. E. Activating the Molecular Spinterface. Nat. Mater. 2017, 16 (5), 507-515. https://doi.org/10.1038/nmat4902.

(27) Jiang, X.; Hao, G.; Wang, X.; Mosey, A.; Zhang, X.; Yu, L.; Yost, A. J.; DiChiara, A. D.; N'Diaye, A. T.; Cheng, X.; Zhang, J.; Cheng, R.; Xu, X.; Dowben, P. A. Tunable Spin-State Bistability in a Spin Crossover Molecular Complex. J. Phys. Condens. Matter 2019, 31 (31). https://doi.org/10.1088/1361-648X/ab1a7d.

(28) Bousseksou, A.; Molnár, G.; Salmon, L.; Nicolazzi, W. Molecular Spin Crossover Phenomenon: Recent Achievements and Prospects. Chem. Soc. Rev. 2011, 40 (6), 3313-3335.

(29) Real, J. A.; Gaspar, A. B.; Carmen Muñoz, M. Thermal, Pressure and Light Switchable Spin-Crossover Materials. Dalton Transactions 2005, pp 2062-2079

(30) Bousseksou, A.; Molnár, G.; Demont, P.; Menegotto, J. Observation of a Thermal Hysteresis Loop in the Dielectric Constant of Spin Crossover Complexes: Towards Molecular Memory Devices. J. Mater. Chem. 2003, 13(9), 2069-2071. 
(31) Ossinger, S.; Näther, C.; Buchholz, A.; Schmidtmann, M.; Mangelsen, S.; Beckhaus, R.; Plass, W.; Tuczek, F.Spin Transition of an Iron(II) Organoborate Complex in Different Polymorphs and in Vacuum-Deposited Thin Films: Influence of Cooperativity. Inorg. Chem. 2020, 59, 7966-7979; doi: 10.1021/acs.inorgchem.9b03354

(32) Wäckerlin, C.; Donati, F.; Singha, A.; Baltic, R.; Decurtins, S.; Liu, S. X.; Rusponi, S.; Dreiser, J. Excited Spin-State Trapping in Spin Crossover Complexes on Ferroelectric $\begin{array}{llllllll}\text { Substrates. J. } & \text { Phys. Chem. } & \text { C 2018, } 122 & \text { (15), 8208. }\end{array}$ https://doi.org/10.1021/acs.jpcc.7b10941.

(33) Costa, P.; Hao, G.; N’Diaye, A. T.; Routaboul, L.; Braunstein, P.; Zhang, X.; Zhang, J.; Doudin, B.; Enders, A.; Dowben, P. A. Perturbing the Spin Crossover Transition Activation Energies in $\mathrm{Fe}(\mathrm{H} 2 \mathrm{~B}(\mathrm{Pz}) 2) 2(B i p y)$ with Zwitterionic Additions. J. Phys. Condens. Matter 2018, 30 (30). https://doi.org/10.1088/1361-648X/aacd7e. 
(34) Carvell, J.; Cheng, R. Study of Electrical Polarization Hysteresis in Ferroelectric Polyvinylidene Fluoride Films. Mater. Lett. 2010, 64 (18), 1992-1995. https://doi.org/10.1016/j.matlet.2010.06.030.

(35) Ducharme, S.; Reece, T. J.; Othon, C. M.; Rannow, R. K. Ferroelectric Polymer Langmuir-Blodgett Films for Nonvolatile Memory Applications. IEEE Trans. Device Mater. Reliab. 2005, 5 (4), 720-735. https://doi.org/10.1109/TDMR.2005.860818.

(36) Palamarciuc, T.; Oberg, J. C.; El Hallak, F.; Hirjibehedin, C. F.; Serri, M.; Heutz, S.; Létard, J.-F.; Rosa, P. Spin Crossover Materials Evaporated under Clean High Vacuum and Ultra-High Vacuum Conditions: From Thin Films to Single Molecules. J. Mater. Chem. 2012, 22 (19), 9690. https://doi.org/10.1039/c2jm15094h.

(37) He, X.; Yao, K.; Gan, B. K. Phase Transition and Properties of a Ferroelectric Poly(Vinylidene Fluoride-Hexafluoropropylene) Copolymer. J. Appl. Phys. 2005, 97 (8). https://doi.org/10.1063/1.1862323. 
(38) Bousseksou, A.; Molnár, G. The Spin-Crossover Phenomenon: Towards Molecular Memories. Comptes Rendus Chim. 2003, 6 (8-10), 1175-1183. https://doi.org/10.1016/j.crci.2003.08.011.

(39) Linares, J.; Nasser, J.; Boukheddaden, K.; Bousseksou, A.; Varret, F. Monte Carlo Simulations of Spin-Crossover Transitions Using the Two-Level Model. I: Mononuclear Single Sublattice Case. J. Magn. Magn. Mater. 1995, 140-144 (PART 3), 1507-1508. https://doi.org/10.1016/0304-8853(94)00913-9.

(40) Chiruta, D.; Linares, J.; Dimian, M.; Alayli, Y.; Garcia, Y. Role of Edge Atoms in the Hysteretic Behaviour of 3D Spin Crossover Nanoparticles Revealed by an Ising-like Model. Eur. J. Inorg. Chem. 2013, No. 29, 5086-5093. https://doi.org/10.1002/ejic.201300757.

(41) Tagantsev, A. K.; Stolichnov, I.; Colla, E. L.; Setter, N. Polarization Fatigue in Ferroelectric Films: Basic Experimental Findings, Phenomenological Scenarios, and Microscopic Features. J. Appl. Phys. 2001, 90 (3), 1387-1402. https://doi.org/10.1063/1.1381542. 
(42) Gomes, J.; Nunes, J. S.; Sencadas, V.; Lanceros-Mendez, S. Influence of the $\beta$ Phase Content and Degree of Crystallinity on the Piezo-and Ferroelectric Properties of

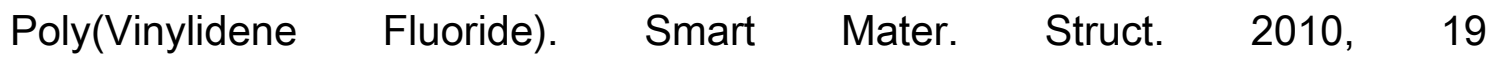
(6). https://doi.org/10.1088/0964-1726/19/6/065010.

(43) Lefter, C.; Davesne, V.; Salmon, L.; Molnár, G.; Demont, P.; Rotaru, A.; Bousseksou, A. Charge Transport and Electrical Properties of Spin Crossover Materials:

Towards Nanoelectronic and Spintronic Devices. Magnetochemistry 2016, 2 (1), 18. https://doi.org/10.3390/magnetochemistry2010018.

(44) Mahfoud, T.; Molnár, G.; Cobo, S.; Salmon, L.; Thibault, C.; Vieu, C.; Demont, P.; Bousseksou, A. Electrical Properties and Non-Volatile Memory Effect of the [Fe(HB(Pz)3)2] Spin Crossover Complex Integrated in a Microelectrode Device. Appl. Phys. Lett. 2011, 99 (5), 1-4. https://doi.org/10.1063/1.3616147.

(45) Baadji, N.; Sanvito, S. Giant Resistance Change across the Phase Transition in Spin-Crossover Molecules. Phys. Rev. Lett. 2012, 108 (21), 1-5. https://doi.org/10.1103/PhysRevLett.108.217201. 
(46) Rotaru, A.; Gural'Skiy, I. A.; Molnár, G.; Salmon, L.; Demont, P.; Bousseksou, A.

Spin State Dependence of Electrical Conductivity of Spin Crossover Materials. Chem.

Commun. 2012, 48 (35), 4163-4165. https://doi.org/10.1039/c2cc30528c.

(47) Li, F.; Huang, J.; Hu, Y.; Li, Q. Transport Property of Ligand-Driven Light-Induced

Spin-Change Fe-Based Spin Crossover Complexes. RSC Adv. 2019, 9 (22), 12339-

12345. https://doi.org/10.1039/C9RA01420A.

(48) Faulmann, C.; Jacob, K.; Dorbes, S.; Lampert, S.; Malfant, I.; Doublet, M.-L.;

Valade, L.; Real, J. A. Electrical Conductivity and Spin Crossover: A New Achievement

with a Metal Bis Dithiolene Complex. Inorg. Chem. 2007, 46 (21), 8548-8559.

https://doi.org/10.1021/ic062461c.

(49) Schleicher, F.; Studniarek, M.; Kumar, K. S.; Urbain, E.; Katcko, K.; Chen, J.;

Frauhammer, T.; Hervé, M.; Halisdemir, U.; Kandpal, L. M.; Lacour, D.; Riminucci, A.;

Joly, L.; Scheurer, F.; Gobaut, B.; Choueikani, F.; Otero, E.; Ohresser, P.; Arabski, J.;

Schmerber, G.; Wulfhekel, W.; Beaurepaire, E.; Weber, W.; Boukari, S.; Ruben, M.;

Bowen, M. Linking Electronic Transport through a Spin Crossover Thin Film to the 
Molecular Spin State Using X-Ray Absorption Spectroscopy Operando Techniques. ACS

$\begin{array}{lllll}\text { Appl. } \quad \text { Mater. Interfaces } & \text { 2018, } 10 \quad \text { (37), }\end{array}$

https://doi.org/10.1021/acsami.8b11495.

(50) Osorio, E. A.; Moth-Poulsen, K.; van der Zant, H. S. J.; Paaske, J.; Hedegård, P.;

Flensberg, K.; Bendix, J.; Bjørnholm, T. Electrical Manipulation of Spin States in a Single Electrostatically Gated Transition-Metal Complex. Nano Lett. 2010, 10 (1), 105-110. https://doi.org/10.1021/nl9029785.

(51) Gopakumar, T. G.; Matino, F.; Naggert, H.; Bannwarth, A.; Tuczek, F.; Berndt, R. Electron-Induced Spin Crossover of Single Molecules in a Bilayer on Gold. Angew. Chemie Int. Ed. 2012, 51 (25), 6262-6266. https://doi.org/10.1002/anie.201201203.

(52) Ruiz, E. Charge Transport Properties of Spin Crossover Systems. Phys. Chem. Chem. Phys. 2014, 16 (1), 14-22. https://doi.org/10.1039/c3cp54028f.

(53) Rotaru, A.; Dugay, J.; Tan, R. P.; Guralskiy, I. A.; Salmon, L.; Demont, P.; Carrey, J.; Molnár, G.; Respaud, M.; Bousseksou, A. Nano-Electromanipulation of Spin 
Crossover Nanorods: Towards Switchable Nanoelectronic Devices. Adv. Mater. 2013, 25

(12), 1745-1749. https://doi.org/10.1002/adma.201203020.

(54) Miyamachi, T.; Gruber, M.; Davesne, V.; Bowen, M.; Boukari, S.; Joly, L.;

Scheurer, F.; Rogez, G.; Yamada, T. K.; Ohresser, P.; Beaurepaire, E.; Wulfhekel, W.

Robust Spin Crossover and Memristance across a Single Molecule. Nat. Commun. 2012,

3 (1), 938. https://doi.org/10.1038/ncomms1940.

(55) Van Geest, E. K.; Shakouri, K.; Fu, W.Y.; Robert, V.; Tudor, V.; Bonnet, S.;

Schneider, G.F. Contactless Spin Switch Sensing by Chemo-Electric Gating of Graphene.

Adv. Mater. 2020, 32, 1903575. https://doi.org/10.1002/adma.201903575. 